\title{
Traumatic carotid and vertebral artery dissection in a professional jockey: a cautionary tale
}

\author{
J. Fletcher, P. T. G. Davies, T. Lewis* and M. J. Campbell \\ Department of Neurology and Neuroradiology*, Frenchay Hospital, Bristol BS16 1LE, UK
}

Jockeys accept bony fractures and soft tissue injuries as occupational hazards. An average National Hunt jockey falls once in ten races with an injury rate of $4.25 \%$. Head injury is a common cause of morbidity and the benefit of helmets is well recognized.

Neck injuries are also common and usually musculoskeletal. Although rare, trauma to the neck arteries may go unnoticed yet have catastrophic consequences. Internal tears can allow arterial blood to dissect the layers of the arterial wall and obstruct the lumen. Severe obstruction may lead to cerebral ischaemia and infarction. An appreciation of the early clinical signs caused by this process may allow effective intervention. We report a case which illustrates these points.

Keywords: carotid artery, dissection, Horner's syndrome, trauma

\section{Case report}

After falling from his horse, a 31-year-old jump jockey was trampled by following horses and received a kick under his left jaw. It was reported that he initially got up onto his knees and spoke but then rapidly became unconscious. Initial hospital examination showed that he was unconscious with his eyes deviated to one side and there was paralysis of the right side of his body. There was a large bruise and superficial laceration over the left side of the neck. Within $15 \mathrm{~min}$ of admission he regained consciousness and was soon alert and orientated with recovery of power on the right side. His pupils were noted to be unequal. Lateral neck X-ray showed a fractured hyoid bone and a CT head scan was normal.

Later that day it was noted that he had drooping of the left eyelid which prompted the correct diagnosis of a left Horner's syndrome but the significance of this was not appreciated at the time. His general condition remained good and he was allowed home 3 days later.

On the fourth night after his accident a major convulsive seizure was witnessed. On recovery he was aphasic with a dense right hemiplegia. Continuing paralysis after several hours prompted urgent transfer to the Department of Neurology at Frenchay Hospital, Bristol, UK.

Address for correspondence: Dr J. Fletcher

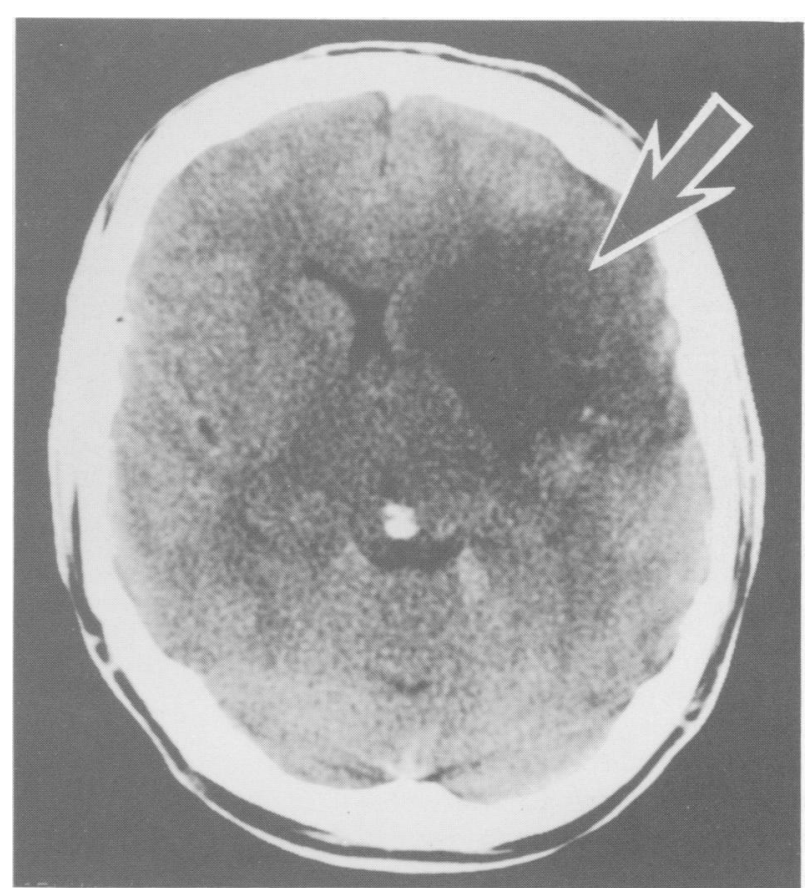

Figure 1. Unenhanced CT brain scan taken 5 days after neck trauma showing a large low density area (arrowed) in the left middle cerebral artery territory

Our examination showed he was aphasic with good comprehension. He was alert and orientated, with a right hemiplegia and a left Horner's syndrome.

A CT scan showed a large established cerebral infarct involving the anterior part of the left middle cerebral artery territory (Figure 1). Angiography, now 5 days after his accident, demonstrated a dissection of the left internal carotid artery in the neck with complete occlusion (Figure 2). The left vertebral artery was also occluded at the upper cervical level (not shown).

Vascular surgery was considered but felt to offer no benefit at this late stage. He began a rehabilitation programme with physiotherapy and speech therapy. At the time of discharge from hospital, 2 months later, he could speak two or three words at a time. He made a limited recovery of speech and walking ability but no useful function of his right hand. 


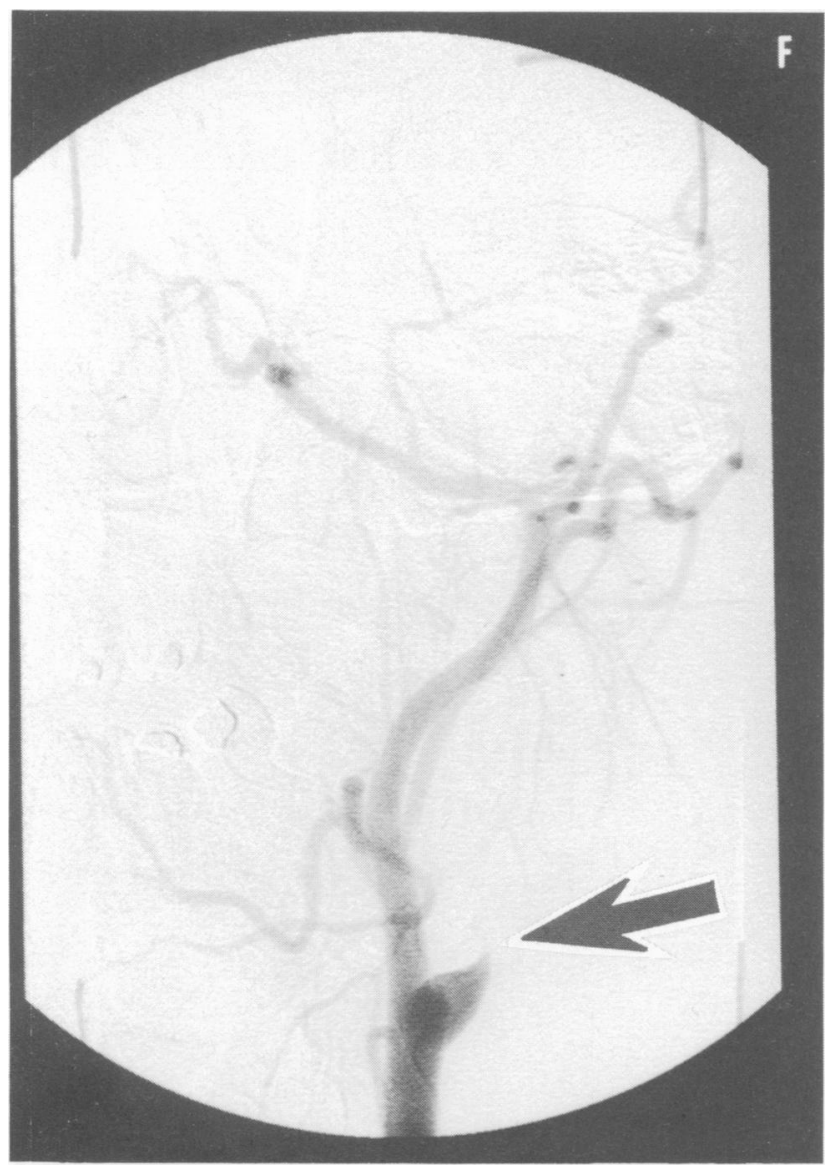

Figure 2. Carotid artery angiogram showing occlusion of the left internal carotid artery just distal to the carotid bifurcation (arrowed)

\section{Discussion}

With advances in imaging techniques, arterial dissections are now readily diagnosed and have been increasingly recognized. They may account for $5 \%$ of ischaemic stroke in young adults ${ }^{2}$. Car accidents, chiropractic manipulation and trampolining are well recognized causes ${ }^{2}$. Cervical rotation and extension causing carotid and vertebral artery compression against bony structures has been postulated as an important mechanism. In $50 \%$ of dissections there will be no sign of neck trauma. In only half the cases will the arterial wall damage be sufficient to disrupt enough sympathetic nerve fibres to produce a Horner's syndrome. This important physical sign may be seen from $1 \mathrm{~h}$ to 5 days after the episode of trauma. Arterial ischaemia to produce focal neurological signs may be delayed for up to 11 days ${ }^{3}$. Major stroke has been reported in up to $20 \%$ of cases and there is a $5 \%$ mortality ${ }^{3}$. Alternatively, it may by asymptomatic as it was with our patient's left vertebral artery occlusion. Treatment may involve arterial reconstruction, ligation and anticoagulation.

The triad of neck injury, Horner's syndrome and contralateral neurological signs should alert the physician to the possibility of arterial dissection. Doppler ultrasound scanning is readily available and will diagnose and define a dissection if present. Prompt recognition is vital for early referral to a specialized unit.

\section{References}

1 Allen WMC. Horse racing injuries. Sports Medicine and Soft Tissue Trauma. 1992; 4:

2 Hart RG, Easton JD. Dissections. Stroke 1985; 16: 925-7.

3 Hart RG, Easton JD. Dissections and trauma of cervicocerebral arteries. In: Stroke, Pathophysiology, Diagnosis and Management. Barnett, et al. eds. Edinburgh, UK: Churchill Livingstone. 1986; 775-88. 